\title{
ADENOMATOID ODONTOGENIC TUMOR OF THE MANDIBLE: AN UNUSUAL CLINICAL PRESENTATION
}

\author{
Rai $A^{1^{*}}$, Dali $M^{2}$, Koirala $B^{3}$, Shrestha $S^{4}$, Acharya $P^{5}$, Shrestha $A^{6}$
}

\section{Affiliation}

1. Postgraduate Resident, Department of Pedodontics and Preventive Dentistry, B.P. Koirala Institute of Health Sciences, Dharan.

2. Associate Professor, Department of Pedodontics and Preventive Dentistry, B.P. Koirala Institute of Health Sciences, Dharan.

3. Professor, Department of Pedodontics and Preventive Dentistry, B.P. Koirala Institute of Health Sciences, Dharan.

4. Assistant Professor, Department of Pedodontics and Preventive Dentistry. B.P. Koirala Institute of Health Sciences, Dharan.

5. Associate Professor, Department of Oral \& Maxillofacial Surgery. B.P. Koirala Institute of Health Sciences, Dharan.

6. Additional Professor, Department of Oral Pathology. B.P. Koirala Institute of Health Sciences, Dharan.

\section{ARTICLE INFO}

\section{Article History}

Received : 18June, 2018

Accepted : 06August, 2018

Published : 31 August, 2018

(C) Authors retain copyright and grant the journal right of first publication with the work simultaneously licensed under Creative Commons Attribution License CC - BY 4.0 that allows others to share the work with an acknowledgment of the work's authorship and initial publication in this journal.

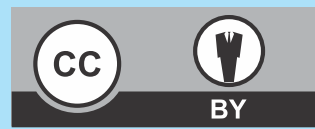

\section{CR 22}

DOI: $\underline{\text { http://dx.doi.org/10.3126/bjhs.v3i2.20971 }}$

\author{
* Corresponding Author \\ Dr. Amita Rai \\ Postgraduate Resident \\ Department of Pedodontics and Preventive Dentistry \\ B.P. Koirala Institute of Health Sciences, Dharan. \\ Email: amitarai2013@gmail.com \\ ORCID: https://orcid.org/0000-0003-2195-6389
}

\section{Citation}

Rai A, Dali M, Koirala B, Shrestha S, Acharya P, Shrestha A. Adenomatoid Odontogenic Tumor of The Mandible: An Unusual Clinical Presentation BJHS 2018;3(2)6: 504-507.

\section{ABSTRACT \\ Introduction}

Adenomatoid odontogenic tumor (AOT) is a rare benign neoplasm of odontogenic epithelial origin. A 12-year-old male reported to the department of pedodontics and preventive dentistry with swelling on lower part of face since seven months. On examination, firm to hard, nontender swelling, sized approximately $3 \times 3 \mathrm{~cm}$, extending from mandibular left canine to right lateral incisor with expansion of labial and lingual cortices was present. Radiograph revealed a well demarcated unilocular radiolucency exhibiting sclerotic border with flecks of calcification and displaced roots of mandibular anteriors and expansion of both cortices. Incisional biopsy confirmed the diagnosis of AOT. Enucleation of the lesion along with \#31, 32 and curettage was done under general anesthesia. Ribbond fiber prosthesis was given to maintain the arch integrity and esthetics. AOT in mandible (35\%) of young male $(36 \%)$ of extrafollicular variant $(24 \%)$ is rare. We may encounter only 2-3 out of 100 AOT cases as typical as the case presented here.

\section{KEYWORDS}

Adenomatoid odontogenic tumor, Mandible, Ribbond prosthesis 


\section{INTRODUCTION}

Adenomatoid odontogenic tumor (AOT) is a benign neoplasm of odontogenic epithelial origin which was first described by Steensland in 1905. In the earlier days AOT was known by the names like adenoameloblastoma, ameloblastic adenomatoid tumor, adamantinoma, epitheliomaadamantinum or teratomatous odontoma. ${ }^{1}$ The term AOT was proposed by Philipsen and Birn in 1969 and World Health Organization (WHO) adopted the name in 1971. ${ }^{2,3}$ AOT usually presents as cystic lesion, but sometimes it may also present as a solid lesion with masses in the wall of a large cyst. ${ }^{4}$ Here, we present a case with an unusual presentation of AOT in anterior mandible causing extensive jaw swelling.

A 12-year-old male reported to the department of Pedodontics and Preventive Dentistry with an asymmetric anterior mandibular swelling. Patient was asymptomatic seven months back when his mother noticed swelling in lower front region of face which was gradually increasing in size with no history of pain, paresthesia, discharge and trauma.

Extra-oral examination revealed a solitary diffuse swelling of size $3 \times 3 \mathrm{~cm}$ on the chin involving midline, more towards the left side. On palpation, the swelling was firm to hard in consistency, non-tender with intact overlying skin and mucosa. (Figure 1) Intra-orally, a swelling extended from \#33-42 involving alveolus with expansion of the labial and lingual cortices. (Figure 2)

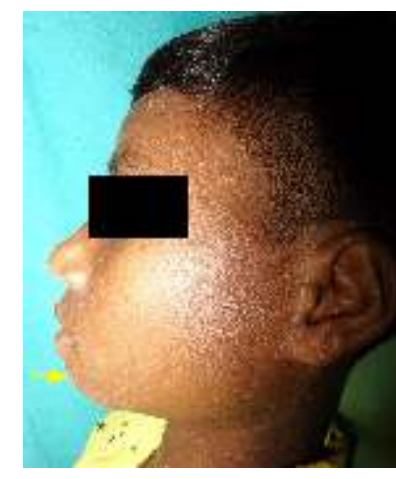

Figure 1: Preoperative lateral view

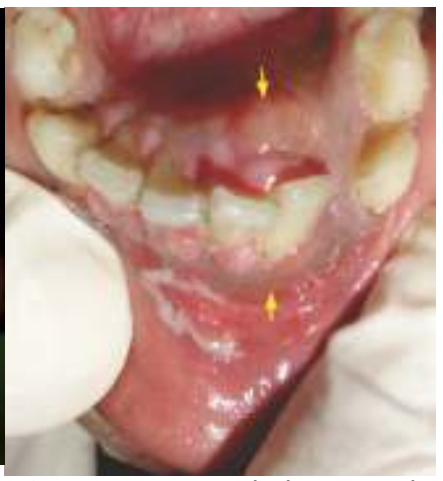

Figure 2: Intraoral photographs showing expansion of buccal and lingual cortices
Radiographs revealed a well-demarcated unilocular radiolucency exhibiting a smooth sclerotic border with flecks of calcification, displaced roots of \#31, 32, 33, 41, 42 and expansion of both cortices. (Figure $3 \mathrm{a}, 3 \mathrm{~b}$ ) Computed

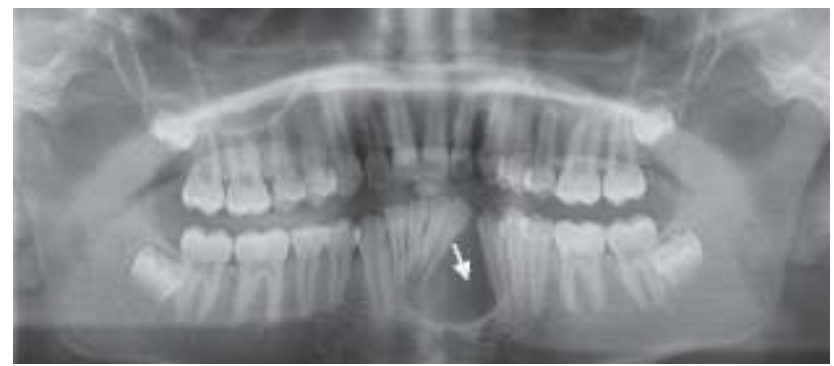

Figure 3a: Orthopantomogram (OPG) showing welldemarcated unilocular radiolucency exhibiting a smooth sclerotic border and the displaced roots of \#31, 32, 33, 41, 42

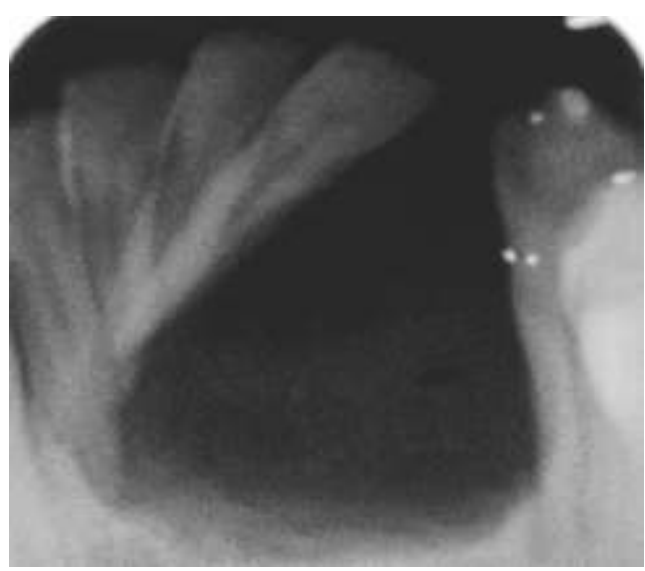

Figure 3b: IOPAR showing well-demarcated unilocular radiolucency exhibiting a smooth sclerotic border with flecks of calcification and the displaced roots of $31,32,33,41,42$

Tomography (CT) scan revealed a large well-defined expansile unilocular lytic lesion with soft tissue component and multiple foci of calcification involving symphysis menti segment of mandible with slight left extension surrounding and causing splaying of roots of left incisors and canine with

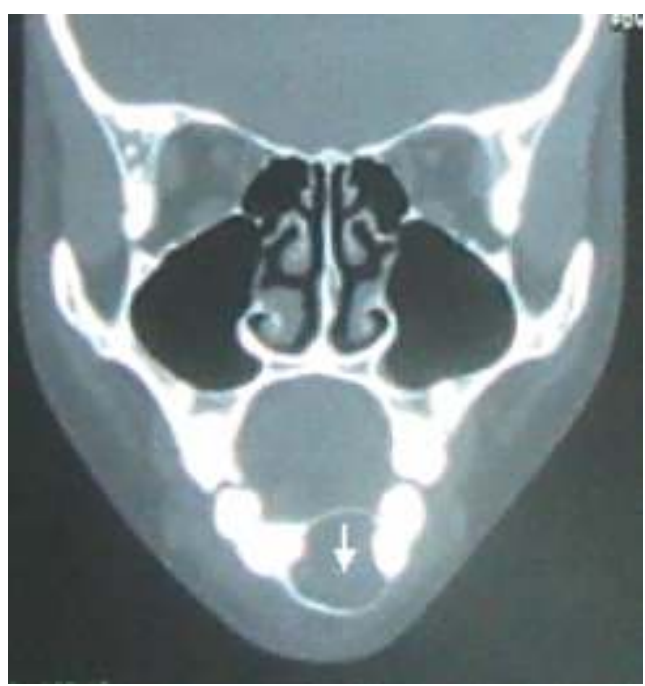

Figure 4: CT Scan, Coronal view

sclerotic margin and breach in the buccal cortex with soft tissue component showing mild enhancement on post contrast study. (Figure 4)

Considering the clinical and radiographic features, differential diagnosis of "Calcifying epithelial odontogenic tumor (CEOT), Unicystic ameloblastoma, Odontogenic keratocyst (OKC), Adenomatoid odontogenic tumor" was made.After routine hematological investigations, incisional biopsy of the lesion was done under local anesthesia. The excised tissue lining was sent for histopathological examination which revealed solid nodules of cuboidal and columnar cells of odontogenic epithelium forming nests or sheets like structures with minimal stromal connective tissue in between. Numerous hyalin like droplets were evident in the stroma. Duct like structures lined by columnar cells with nuclei away from the lumen were evident with eosinophilic hyalin ring. Numerous basophilic aggregates of irregular calcifications were also noted. Underlying surrounding connective tissue

\begin{tabular}{ll} 
& Birat Journal of Health Sciences \\
\hline ISSN $2542-2758$ (Print) 2542-2804 (Online) & Vol.3/No.2/Issue 6/ May-August 2018
\end{tabular}


comprised of mature fibrous stroma with numerous odontogenic cell rests. (Figure 5a, 5b) Based on clinical, radiographic, and histopathological examination, final diagnosis of adenomatoid odontogenic tumor was made.

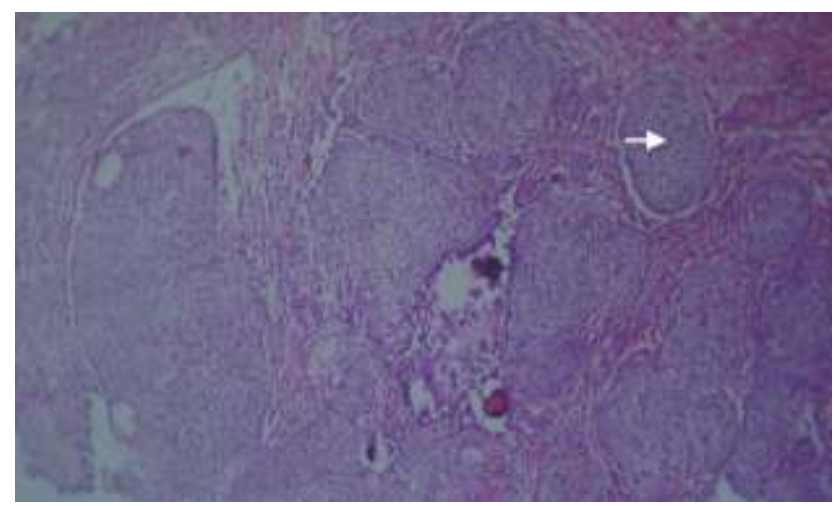

Figure 5 (a) Histopathology pictures(40X) Eosinophilic Tumor Droplets

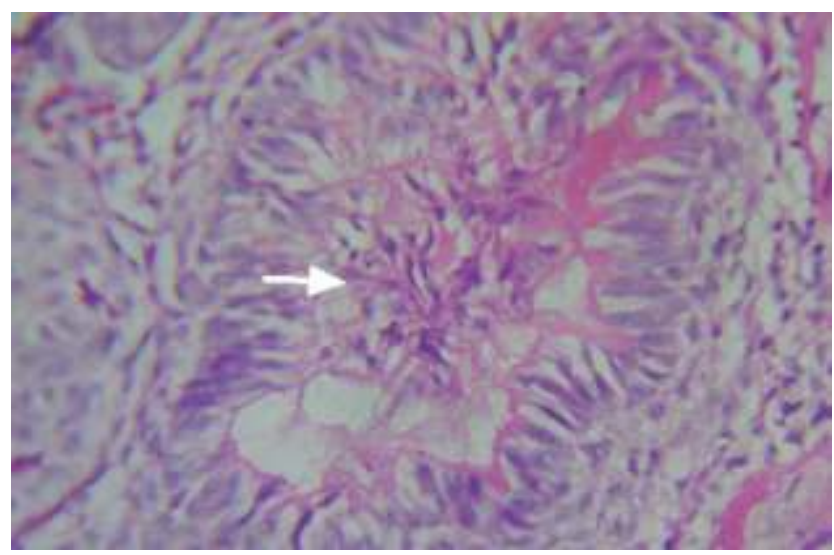

Figure 5 (b) Histopathology pictures(100X) Single Rosette

After incisional biopsy report, surgical enucleation of the lesion along with \#31, 32 and curettage was done under general anesthesia. (Figure 6a, 6b) On sixth week follow up, electric pulp testing (EPT) of mandibular anterior teeth was done. Endodontic treatment of \#41 was done as it was nonresponsive to EPT. Rehabilitation of the edentulous segment was done with ribbond fiber prosthesis. (Figure 7) Patient is under regular follow up with evidence of adequate bone formation and no recurrence till 18 months. (Figure 8b)

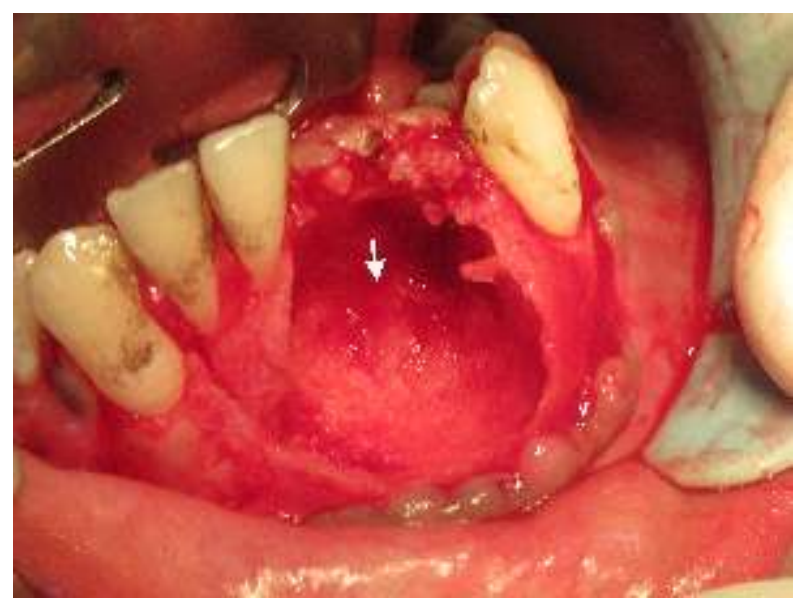

Figure 6a: Enucleation and curettage of the lesion

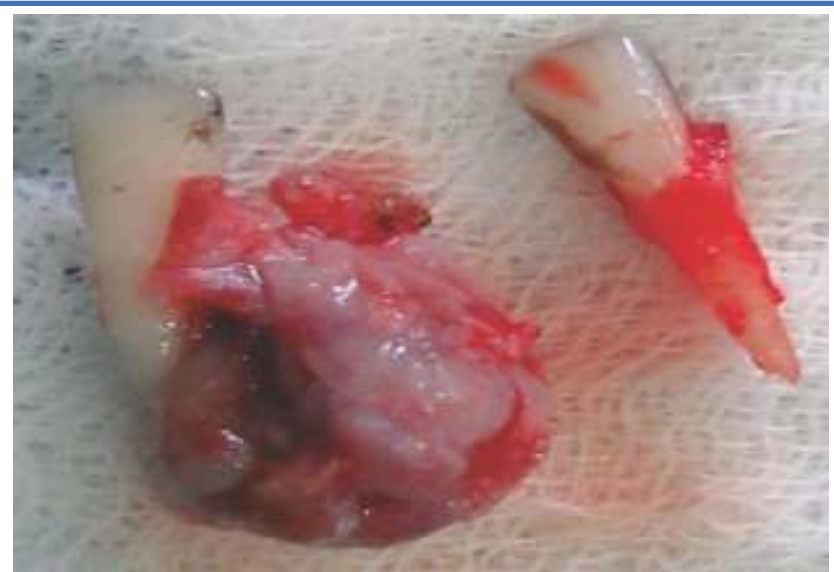

Figure 6b: Enucleated mass

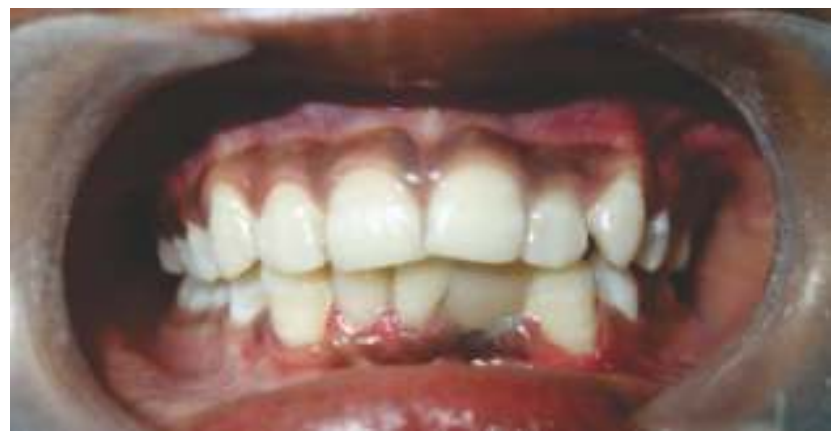

Figure 7: Rehabilitation of the edentulous segment with ribbond fiber prosthesis

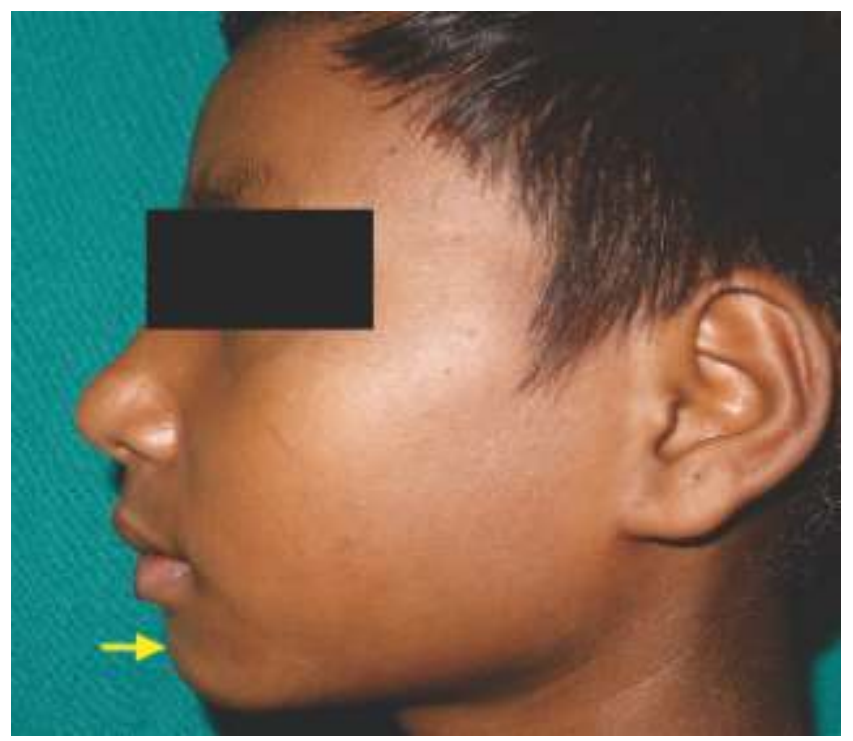

Figure 8a: 9 months postoperative lateral view

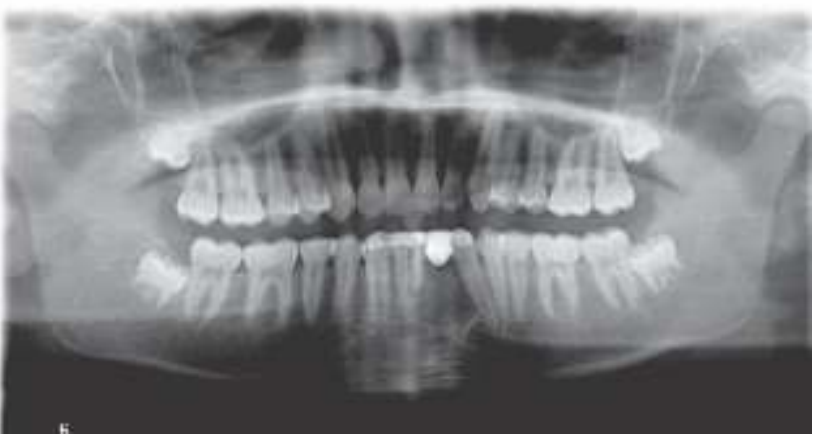

Figure 8b: 18-months follow up OPG 


\section{DISCUSSION}

Adenomatoid odontogenic tumor is slow growing, uncommmon odontogenic tumor with a prevalence of $2.2 \%$ to $7.1 \%$. It is also known as two-third $\left(2 / 3^{\text {rd }}\right)$ tumor as it occurs in maxilla in about $2 / 3^{\text {rd }}$ cases, about $2 / 3^{\text {rd }}$ in females, $2 / 3^{\text {rd }}$ cases are associated with unerupted/impacted tooth, and $2 / 3^{\text {rd }}$ teeth affected are canines. ${ }^{5}$ The tumor is usually $1-3 \mathrm{~cm}$ in maximum diameter, but larger sizes may also be encountered. ${ }^{2}$

Philipsen et al. divided AOT as three variants; follicular (73\%), extrafollicular (24\%) and peripheral (3\%). ${ }^{6}$ Follicular variant presents as central intraosseous lesion associated with an unerupted tooth, whereas extrafollicular variant is not related to unerupted teeth. It is often present between, above, and sometimes superimposed upon the roots of adjacent erupted teeth. ${ }^{7}$ Divergence of roots and displacement of adjacent teeth occurs more often than root resorption. The peripheral variant of AOT often presents as gingival fibroma or epulis attached to the labial gingiva. ${ }^{6}$ Present case report illustrates characteristic clinical and radiographic features of the extrafollicular variant of AOT.

Radiographically AOT frequently resembles other odontogenic lesions like dentigerous cyst, calcifying odontogenic cyst, ameloblastoma, OKC and CEOT. The follicular variant has distinct radiological features: pericoronal radiolucency surrounding an unerupted tooth, whereas extrafollicular AOT is usually confused with other more common cysts and tumors. Both variants of AOT present radiographically as well-circumscribed unilocular radiolucency or sometimes may also present as mixed (radiopaque and radiolucent) lesion with well-defined corticated or sclerotic border, and in approximately $78 \%$ of cases, multiple minute calcifications or radiopaque foci of different shapes presenting as 'cluster of small pebbles' may also be seen, which was also seen in present case. ${ }^{8}$

In 2005 the histologic typing of WHO defined AOT as "Tumor composed of odontogenic epithelium presenting a variety of histoarchitectural patterns, embedded in a mature connective tissue stroma, and characterized by slow but progressive growth." ${ }^{5}$ All variants of AOT have common histologic characteristics indicating a common origin: complex system of dental lamina or its remnants. ${ }^{2}$

AOT is usually treated by surgical enucleation or curettage and the recurrence is rare. ${ }^{9}$ However, if the size of the lesion is large, partial or en bloc resection of the jaw is done, followed by use of lyophilized bone and guided tissue regeneration to strengthen the osseous defect. ${ }^{8}$

\section{CONCLUSIONS}

Sometimes an unusual pathology may disguise us with common findings. An unusual presentation of AOT; extrafollicular type in anterior mandible of a young male was diagnosed with timely interpretation of clinical, radiological and histological findings and was managed surgically and the edentulous space was rehabilitated with fixed prosthesis. When examining a patient, we should never stop keeping ones' eyes and mind open and thinking out of the box.

\section{CONFLICT OF INTEREST}

None

\section{FINANCIAL DISCLOSURE}

None

\section{REFERENCES}

1. Handschel J, Depprich RA, Zimmermann AC, Braunstein S, Kubler NR. Adenomatoid odontogenic tumor of the mandible: Review of the literature and Report of a rare case. Head \& Face Medicine 2005; 1: 1-5. DOI:10.1186/1746-160X-1-3

2. Subramaniam K, Sachidhananadan MK, Manoharan S, Elangovan M. Adenomatoid odontogenic tumor of the mandible. J Indian Aca Oral Med Radiol2010; 24:66-9.DOI:10.5005/JP-JOURNALS-10011-1262

3. Philipsen HP, Reichart PA. Adenomatoid odontogenic tumour: Facts and figures. Oral Oncol1999; 35:125-31. PMID:10435145

4. Kramer IRH, Pindborg JJ, Shear M. WHO International histological classification of tumors $\left(2^{\text {nd }} \mathrm{ed}\right)$. Histological typing of odontogenic tumors. Berlin: Springer Verlag 1992.DOI:10.1007/978-3-66202858-2

5. Garg D, Palaskar S, Shetty VP, Bhushan A. Adenomatoid odontogenic tumor-hamartoma or true neoplasm: A case report. J Oral Sci 2009;51:155-9.PMID: 19325215
6. Philipsen HP, Reichart PA, Nikai H. The adenomatoid odontogenic tumour (AOT): An update. J Oral Pathol1997; 2:55-60.DOI:ORG/ 10.3353/OMP.2.55

7. Philipsen HP, Srisuwan T, Reichart PA. Adenomatoid odontogenic tumor mimicking a periapical (radicular) cyst: A case report. Oral Surg Oral Med Oral Pathol Oral RadiolEndod2002; 94:246-8. DOI:10.1067/MOE.2002.124767

8. More CB, Das S, Gupta S, Bhavsar K. Mandibular adenomatoid odontogenic tumor: Radiographic and pathologic correlation. J Nat SciBiol Med 2013; 4: 457-62.DOI: 10.4103/09769668.116965

9. Philipsen HP, Reichart PA, Zhang KH, Nikai H, Yu QX. Adenomatoid odontogenic tumor: Biologic profile based on 499 cases. J Oral Pathol Med 1991; 20:149-58.PMID:2061853 